\title{
Effect of reduced dietary protein intake on hepatic and plasma essential fatty acid concentrations in the adult female rat: effect of pregnancy and consequences for accumulation of arachidonic and docosahexaenoic acids in fetal liver and brain*
}

\author{
Graham C. Burdge†, Rebecca L. Dunn, Stephen A. Wootton and Alan A. Jackson \\ Institute of Human Nutrition, University of Southampton, Hants., UK \\ (Received 10 September 2001 - Revised 18 March 2002 - Accepted 16 May 2002)
}

\begin{abstract}
During pregnancy, the accumulation of long-chain polyunsaturated fatty acids (LCPUFA) in fetal tissues places a substantial demand upon maternal lipid metabolism. As lipid metabolism is intimately linked to aspects of protein metabolism, a reduced protein intake in pregnancy may impair activities of enzymes and transport proteins responsible for supplying LCPUFA to the fetus, thereby compromising fetal development. We have investigated the effect of reduced protein intake on LCPUFA status in the non-pregnant rat and in the pregnant rat, and in fetus at day 20 of gestation. Female rats ( 55 per group) were either mated and fed the control diet $(180 \mathrm{~g}$ protein $/ \mathrm{kg})$ or low-protein diet $(90 \mathrm{~g}$ protein $/ \mathrm{kg}$, LPD) diet throughout pregnancy, or fed the control diet or LPD for $20 \mathrm{~d}$ (non-pregnant animals). The fatty acid compositions of maternal liver and plasma, and fetal liver and brain were determined by GC. Feeding the LPD did not lead to any gross changes either in adult or fetal growth, or in total lipid concentrations in adult rat liver. However, the LPD was associated specifically with lower liver $(42.6 \%)$ and plasma (19.4\%) phosphatidylcholine (PC), and plasma triacylglycerol (28.6\%) docosahexaenoic acid (DHA) concentrations in pregnant rats and reduced fetal brain PC- $(26.1 \%)$ and phosphatidylethanolamine- $(25.6 \%)$ DHA concentrations. Together, these results show that variations in maternal dietary protein consumption alter DHA status in pregnancy and modify DHA accumulation into the fetal brain. The present results suggest that lower maternal protein intakes reduce delivery of DHA from the mother to the fetus, which may impair development and function of the fetal brain.
\end{abstract}

Low-protein diet: Pregnancy: Docosahexaenoic acid: Brain: Rat

Long-chain polyunsaturated fatty acids (LCPUFA) are an integral part of all cell membranes and critical for normal cellular function. Thus, there is an absolute requirement for normal fetal growth (Koletzco \& Braun, 1991; Leaf et al. 1992) and a special requirement for the development of specific tissues, such as the brain and retina (Leat et al. 1986; Neuringer et al. 1988; Innis, 1991; Salem \& Niebylski, 1995). Inadequate incorporation of docosahexaenoic acid (DHA) into the membrane phospholipids of neural tissue can lead to persistent deficits in function in animal models (Connor et al. 1990; Riesbick et al. 1990, 1994; Neuringer et al. 1984; Leat et al. 1986) and in preterm human infants (Uauy et al. 1990). The timing of any limitation of DHA availability for brain development may be critical, as DHA is accumulated over a period corresponding principally to the major phase of neuritogenesis. Any deficit in DHA assimilation during this period may not be repaired by subsequent supplementation (Connor et al. 1990).

The precursors linoleic acid (LA) and $\alpha$-linolenic acid (ALNA) are typically the predominant LCPUFA in the diets of both man and laboratory animals. Longer-chain LCPUFA, such as DHA or arachidonic acid (AA), are formed in the liver through metabolic conversion: desaturation

Abbreviations: AA, arachidonic acid (20:4n-6); ALNA, $\alpha$-linolenic acid (18:3n-3); DGLA, dihomo- $\gamma$-linolenic acid (20:3n-6); DPA, docosapentaenoic acid (22:5n-3); LA, linoleic acid (18:2 n-6); LCPUFA, long-chain polyunsaturated fatty acid; LPD, low-protein diet; NEFA, non-esterified fatty acid; PC, phosphatidylcholine; PE, phosphatidylethanolamine; TAG, triacylglycerol.

*These results have been described previously, in part, in an abstract (Burdge GC, Wright P, Dunn R, Wootton SA \& Jackson AA (2001) Effect of feeding a low-protein diet on liver and plasma phosphatidylcholine $n-3$ fatty acid concentrations in the adult rat. Proceedings of the Nutrition Society 60, 187A). $\dagger$ Corresponding author: Dr G. C. Burdge, fax +44 23 80794945, email G.C.Burdge@ soton.ac.uk 
and chain elongation. To a substantial degree, the fetus is dependent upon the mother for a supply of pre-formed DHA and AA, because the capacity of the fetal liver for desaturation and chain-elongation is not mature in early gestation in rats (Li et al. 2000), pigs (Chambaz et al. 1985) or human subjects (Sanders \& Rana, 1987). Although desaturation and elongation of LA and/or ALNA has been demonstrated in the near-term fetuses of both non-human primate (Su et al. 1999a,b) and human subjects (Demmelmair et al. 1995; Carnielli et al. 1996; Salem et al. 1996; Sauerwald et al. 1997), this capacity appears to be limited and its contribution compared with the mother for meeting fetal demands for LCPUFA has not been defined. The ability of the mother to satisfy fetal demands for AA and DHA will depend upon her capacity for inter-conversion of LA and ALNA, for mobilisation of LCPUFA, principally from the liver, and for transfer within the maternal circulation to the placenta and fetus. Any reduction in the activities of enzymes and transporter proteins responsible for these processes would potentially limit the ability of the mother to supply adequate LCPUFA to the fetus, which would in turn have important consequences for fetal development and subsequent function in later life.

Pregnancy is associated with hyperlipidaemia, which is thought to facilitate the transfer of lipid from the mother to the fetus. In addition, there is a specific increase in the DHA content of plasma phosphatidylcholine (PC) and/or triacylglycerol (TAG) in several species (Neuringer et al. 1984; Chen et al. 1992; Burdge et al. 1994; Burdge \& Postle, 1994; Postle et al. 1995; Otto et al. 1997). There is progressive DHA enrichment from maternal liver to fetal liver (biomagnification) (Crawford et al. 1976), suggestive of a substantial drive within the mother to deliver DHA. These adaptations have the appearance of facilitating the supply of DHA to the fetus from the mother, as for the human subject and guinea-pig the timing of the increase in DHA concentration in plasma coincides with the principle period of DHA accumulation into fetal brain (Clandinin et al. 1980a,b; Burdge \& Postle, 1995a). It seems likely that these adaptations in DHA status in the mother are specific and enable the demands of developing fetal brain to be met. By contrast, for the pregnant rat, the increase in plasma PC-DHA concentration preceded the principle phase of DHA assimilation into developing brain in the neonatal period (Sinclair \& Crawford, 1972), perhaps to increase DHA availability in anticipation of the needs for lactation. In pregnant women, rats and guineapigs increased plasma PC-DHA concentration was due to a selective increase in plasma 1-palmitoyl, 2-docosahexaenoyl PC (Burdge et al. 1994; Burdge \& Postle, 1994; Postle et al. 1995). In the rat, this was due to increased DHA concentration in maternal hepatic diacylglycerol pools used as substrates for PC synthesis, greater cytidine $5^{\prime}$-diphosphate: choline 1,2-diacylglycerol cholinephosphotransferase activity and increased PC synthesis de novo (Burdge et al. 1994).

There are important interactions between lipid metabolism and protein metabolism. The consumption of a diet with reduced protein content impairs the synthesis of proteins involved in both LCPUFA synthesis and mobilisation of lipid from the liver (Jackson et al. 2001). Dietary protein intake has been shown to regulate $\Delta 6$-desaturation in hepatic microsomes from non-pregnant adult female rats (Peluffo \& Brenner, 1974). In the pregnant rat, feeding a diet containing $50 \mathrm{~g}$ protein $/ \mathrm{kg}$ reduced maternal $\Delta 6$-desaturase activity, the rate-limiting step in LCPUFA synthesis (Sprecher et al. 1999), at day 20 of gestation compared with controls fed $250 \mathrm{~g}$ protein/kg (De Thomas et al. 1983). This was associated with lower hepatic phospholipid DHA concentration in the pups at weaning, which was reversed by cross-fostering the pups at birth to mothers consuming a control diet ( $250 \mathrm{~g}$ protein $/ \mathrm{kg}$ ). Reduced hepatic $\Delta 5$-desaturase activity at 3 months of age has also been reported in the offspring of mothers fed $80 \mathrm{~g}$ protein $/ \mathrm{kg}$ diet during pregnancy (Ozanne et al. 1998). Marin et al. (1995) found a progressive reduction in brain weight and phospholipid content of the pups when pregnant rats were fed diets containing 250, 150, 100 or $50 \mathrm{~g}$ protein $/ \mathrm{kg}$. Thus, variations in maternal protein intake may both modify LCPUFA supply to the fetus and programme the essential fatty acid metabolism in the offspring, possibly by altering capacity for synthesis of hepatic $\Delta 6$ - and $\Delta 5$-desaturases.

None of the preceding studies reported the effects of feeding a low-protein diet (LPD) on maternal LCPUFA status during pregnancy or upon accumulation of LCPUFA into fetal tissues. A reduction (50\%) in dietary protein intake in pregnancy in the rat is associated with marked alterations to the physiology of the offspring (Langley \& Jackson, 1994; Langley-Evans et al. 1999). One mechanism by which this dietary modification may act is by reducing maternal capacity for synthesis of enzymes and proteins involved in lipid transfer to the fetus. In the present study, we have fed non-pregnant and pregnant female rats a diet with a reduced protein content $(50 \%)$ to test the hypothesis that feeding a LPD in pregnancy decreases maternal LCPUFA status leading to lower levels of these fatty acids in fetal tissues at term. We report total lipid and LCPUFA concentrations in liver and plasma from both non-pregnant rats and in pregnant adult rats, and fetal liver and brain at day 20 of gestation.

\section{Materials and methods}

\section{Materials}

Solvents were purchased from Fisher Chemicals Limited (Loughborough, Leics., UK). Lipid standards and other regents were from Sigma (Poole, Dorset, UK). Solidphase extraction cartridges were from Varian (Walton-onThames, Surrey, UK).

\section{Animal procedures}

Virgin female Wistar rats were assigned ( $n 5$ per dietary group) to a diet containing either 180 (control) or 90 (LPD) g protein/kg (Langley \& Jackson, 1994) and maintained on these diets for $20 \mathrm{~d}$. The nutrient compositions of these diets are summarised in Table 1. A second group of rats were mated and maintained on the control or LPD diets ( $n 5$ per dietary group) until day 20 of gestation. All procedures were carried out in accordance 
Table 1. Composition $(\mathrm{g} / \mathrm{kg})$ of the control and low-protein diets*

\begin{tabular}{lcc}
\hline Diet... & Control & LPD \\
\hline Casein & 180 & 90 \\
Maize starch & 425 & 485 \\
Sucrose & 213 & 243 \\
Choline & 2 & 2 \\
Methionine & 5 & 5 \\
Vitamins & 5 & 5 \\
Minerals & 20 & 20 \\
Cellulose & 50 & 50 \\
Magnesium sulfate & 0.5 & 0.5 \\
Maize oil† & 100 & 100 \\
\hline
\end{tabular}

LPD, low protein diet.

* The diets were isoenergetic (control 20.2 MJ/kg, LPD 19.9 MJ/kg).

$\dagger$ The maize oil contained ( $\mathrm{g} / \mathrm{kg}$ diet): palmitic acid 11.6, stearic acid 1.6, oleic acid $30 \cdot 9$, linoleic acid $54 \cdot 9, \alpha$-linolenic acid $0 \cdot 7$.

with Home Office regulations. Adult rats were sacrificed by $\mathrm{CO}_{2}$ asphyxiation. Blood was collected from adults by cardiac puncture using lithium heparin as anticoagulant and plasma isolated by centrifugation at $1125 \mathrm{~g}$ for $15 \mathrm{~min}$ at $4^{\circ} \mathrm{C}$. Maternal liver, and fetal liver and brain were excised rapidly and frozen immediately in liquid $\mathrm{N}_{2}$. Plasma and tissues were stored at $-20^{\circ} \mathrm{C}$.

\section{Isolation of lipids and analysis of fatty acid compositions}

Liver, brain and plasma total lipid extracts were prepared by a modification of Folch et al. (1957) as described by Burdge et al. (2000). Briefly, tissues were homogenised in $0.8 \mathrm{ml} 0.15 \mathrm{M}-\mathrm{NaCl}$. Dipentadecanoyl PC, diheptadecanoyl phosphatidylethanolamine (PE), heneicosanoic acid and triheptadecanoin were added to the tissue homogenates or plasma $(1.0 \mathrm{ml})$ as recovery standards as appropriate. Total lipids were isolated by extraction with chloroformmethanol (2: 1, v/v) containing butyrated hydroxytoluene $(50 \mu \mathrm{g} / \mathrm{ml})$, the organic phase collected and dried under $\mathrm{N}_{2}$ at $40^{\circ} \mathrm{C}$ (Burdge et al. 2000). TAG, PC, PE and nonesterified fatty acids (NEFA) were isolated by solid-phase extraction on aminopropylsilica cartridges $(100 \mathrm{mg})$ and fatty acid methyl esters prepared using methanol containing $\mathrm{H}_{2} \mathrm{SO}_{4}(20 \mathrm{ml} / \mathrm{l})$ (Burdge et al. 2000).

Fatty acid methyl esters were resolved using a Hewlett Packard 5890 GC (Hewlett Packard, Wokingham, Berks., UK) equipped with a $50 \mathrm{~m} \times 0.25 \mu \mathrm{m} \times 0.32 \mathrm{~mm}$ BPX-70 fused silica capillary column (SGE Europe Limited, Milton Keynes, Bucks., UK) and GC-flame ionisation detection. Data were acquired and processed using Chemstation software (Hewlett Packard). Peaks were identified routinely by retention times relative to authentic standards. These identities were confirmed in representative specimens by comparison of electron impact ionisation spectra generated by GC-MS under identical chromatographic conditions to the $\mathrm{GC}$-flame ionisation detection analysis with those produced by authentic standards (results not shown). Fatty acid concentrations were determined relative to the internal standard. Total lipid concentrations were calculated from summation of individual fatty acid concentrations, corrected for mol fatty acid/mol TAG, PC or PE.

\section{Statistical analysis}

Data are presented as mean values and standard deviations. Statistical analysis of the results from adult animals was by ANOVA using Bonferroni's correction for post-hoc analysis of multiple comparisons. Analysis of data from fetuses was carried out using Students unpaired $t$ test.

\section{Results}

\section{Adult and fetal growth and tissue weights}

There was no significant weight gain in the non-pregnant animals over the $20 \mathrm{~d}$ of the study, while the pregnant rats showed equivalent weight gains in both dietary groups (control 35.0\%, LPD 31.5\%) (Table 2). There were no statistically significant differences between dietary groups in starting or final weight. Adult liver weights did not differ significantly between groups. However, for both the control and LPD rats liver weights were greater $(P<0.01)$ in the pregnant animals compared with nonpregnant animals (control $41.1 \%$, LPD $40.9 \%$ ). There were no significant differences between dietary groups in placental or fetal carcass, liver or brain weights (Table 2).

\section{Effect of pregnancy and reduced protein intake on total lipid concentrations in adult liver and plasma}

There were no significant differences between dietary groups in liver and plasma total lipid concentrations in non-pregnant rats (Table 3 ). In addition, there was no effect of pregnancy upon liver PC, PE and TAG concentrations or in plasma PC and NEFA levels (Table 3). Plasma TAG was increased significantly in both the control (3.2-fold) and LPD (3.4-fold) groups relative to the nonpregnant animals, but there was no significant difference between groups in plasma TAG concentration in pregnancy at day 20 (Table 3).

\section{Effect of pregnancy and reduced protein intake on adult rat liver and plasma long-chain polyunsaturated fatty acid concentrations}

Pregnancy was associated with decreased concentrations of hepatic PC-dihomo- $\gamma$-linolenic acid (DGLA) (control $41.4 \%$, LPD $35.2 \%$ ), AA (control $33.0 \%$, LPD $33.4 \%$ ) and DPA (control 50.0\%, LPD $48.5 \%$ ) (Table 4). There was no significant difference in LA concentration between non-pregnant and pregnant animals. In contrast, hepatic PC-DHA concentration was significantly greater in pregnant rats fed the control diet $(39.2 \%)$. However, there was no significant difference in liver PC-DHA concentration between non-pregnant and pregnant animals fed the LPD (Table 4). Thus, feeding a reduced-protein diet resulted in significantly $(P<0.005)$ lower maternal hepatic DHA concentration in pregnancy $(42.6 \%)$ compared with animals fed the control diet.

Pregnancy was associated with decreased hepatic PELCPUFA concentrations in animals in both dietary groups (Table 4), while liver TAG- $n-3$ and $-n-6$ fatty acid contents were not affected significantly by pregnancy. 
Table 2. Whole-body and tissue weights of adult and fetal rats§ (Mean values and standard deviations)

\begin{tabular}{|c|c|c|c|c|}
\hline & \multicolumn{4}{|c|}{ Dietary group } \\
\hline & \multicolumn{2}{|c|}{ Control } & \multicolumn{2}{|c|}{ LPD } \\
\hline & Mean & SD & Mean & SD \\
\hline \multicolumn{5}{|l|}{ Adult non-pregnant ( $n 5$ per group) } \\
\hline Whole-body weight at start $(\mathrm{g})$ & 262 & 18 & 265 & 11 \\
\hline Whole-body weight at $20 \mathrm{~d}(\mathrm{~g})$ & 272 & 18 & 282 & 14 \\
\hline Liver weight $(\mathrm{g})$ & 9.5 & 0.9 & 8.8 & 1.5 \\
\hline \multicolumn{5}{|l|}{ Adult pregnant ( $n 5$ per group) } \\
\hline Whole-body weight at start of pregnancy (g) & 260 & 16 & 254 & 14 \\
\hline Whole-body weight at $20 \mathrm{~d}(\mathrm{~g})$ & $351^{*} \ddagger$ & 32 & $334^{*} \ddagger$ & 28 \\
\hline Liver weight $(\mathrm{g})$ & $12 \cdot 7^{+}$ & 1.0 & $12 \cdot 4^{+}$ & $2 \cdot 0$ \\
\hline \multicolumn{5}{|l|}{ Placenta ( $n 20$ per group)\| } \\
\hline Weight $(\mathrm{g})$ & 0.53 & 0.13 & 0.54 & 0.11 \\
\hline \multicolumn{5}{|l|}{ Fetus ( $n 20$ per group)\| } \\
\hline Carcass weight $(\mathrm{g})$ & 3.44 & 0.4 & 3.46 & 0.59 \\
\hline Liver weight (q) & 0.26 & 0.07 & 0.27 & 0.09 \\
\hline Brain weight $(\mathrm{g})$ & 0.14 & 0.01 & 0.14 & 0.02 \\
\hline \multicolumn{5}{|c|}{$\begin{array}{l}\text { LPD, low-protein diet. } \\
\text { Mean values were significantly different from those of non-pregnant animals within the same dietary group: } \\
{ }^{*} P<0.01 \text {. }\end{array}$} \\
\hline \multicolumn{5}{|c|}{$\begin{array}{l}\text { Mean values were significantly different from those at the start of pregnancy within the same dietary group: } \\
\ddagger P<0.0005 \text {. } \\
\S \text { For details of diets and procedures, see Table } 1 \text { and pp. } 380-381 \text {. }\end{array}$} \\
\hline
\end{tabular}

DPA was not detected in liver TAG in either non-pregnant or pregnant rats.

Plasma PC-LA, -DGLA, -AA and -DPA concentrations were not altered significantly by either pregnancy or by feeding diets with differing protein contents (Table 5).

Table 3. Adult rat liver and plasma total lipid concentrationsł (Mean values and standard deviations for five rats per group)

\begin{tabular}{|c|c|c|c|c|}
\hline & \multicolumn{4}{|c|}{ Dietary group } \\
\hline & \multicolumn{2}{|c|}{ Control } & \multicolumn{2}{|c|}{ LPD } \\
\hline & Mean & $\mathrm{SD}$ & Mean & $\mathrm{SD}$ \\
\hline \multicolumn{5}{|l|}{ Liver } \\
\hline \multicolumn{5}{|l|}{ Non-pregnant } \\
\hline $\mathrm{PC}(\mu \mathrm{mol} / \mathrm{g})$ & $15 \cdot 7$ & $3 \cdot 2$ & $13 \cdot 7$ & 0.7 \\
\hline $\mathrm{PE}(\mu \mathrm{mol} / \mathrm{g})$ & 4.9 & $1 \cdot 1$ & $4 \cdot 7$ & 0.1 \\
\hline TAG $(\mu \mathrm{mol} / \mathrm{g})$ & 3.6 & 0.7 & $3 \cdot 0$ & 1.6 \\
\hline \multicolumn{5}{|l|}{ Pregnant } \\
\hline $\mathrm{PC}(\mu \mathrm{mol} / \mathrm{g})$ & $16 \cdot 5$ & 1.0 & $14 \cdot 6$ & 0.5 \\
\hline $\mathrm{PE}(\mu \mathrm{mol} / \mathrm{g})$ & 4.0 & 0.5 & 3.5 & 0.5 \\
\hline $\mathrm{TAG}(\mu \mathrm{mol} / \mathrm{g})$ & $3 \cdot 2$ & 0.7 & $4 \cdot 1$ & 0.6 \\
\hline \multicolumn{5}{|l|}{ Plasma } \\
\hline \multicolumn{5}{|l|}{ Non-pregnant } \\
\hline $\mathrm{PC}(\mathrm{mmol} / \mathrm{l})$ & 0.8 & 0.2 & 0.9 & 0.1 \\
\hline NEFA $(\mathrm{mmol} / \mathrm{l})$ & 0.8 & 0.1 & $1 \cdot 1$ & 0.1 \\
\hline TAG $(\mathrm{mmol} / \mathrm{l})$ & 0.9 & 0.2 & 0.9 & 0.3 \\
\hline \multicolumn{5}{|l|}{ Pregnant } \\
\hline $\mathrm{PC}(\mathrm{mmol} / \mathrm{l})$ & 1.0 & 0.2 & 1.4 & 0.3 \\
\hline NEFA (mmol/l) & $1 \cdot 2$ & 0.1 & 1.4 & 0.1 \\
\hline TAG $(\mathrm{mmol} / \mathrm{l})$ & $2 \cdot 9^{\star \star \star \star}$ & 0.3 & $3 \cdot 1^{\star \star \star \star}$ & 0.7 \\
\hline
\end{tabular}

LPD, low-protein diet; PC, phosphatidylcholine; PE, phosphatidylethanolamine; TAG, triacylglycerol; NEFA, non-esterified fatty acid.

Mean values were significantly different from those of non-pregnant animals within the same dietary group: ${ }^{\star * * *} P<0.0001$.

‡For details of diets and procedures, see Table 1 and pp. 380-381.
Plasma PC-DHA concentration was significantly greater in pregnant animals (control 80.0\%, LPD 32.8\%). However, plasma PC-DHA concentration in pregnant rats was significantly lower in those fed the LPD $(19.4 \%)$ compared with controls (Table 5). There were no effects of either pregnancy or diet upon plasma NEFA-LCPUFA composition or plasma TAG-DGLA or -DPA concentrations (Table 5). DGLA and DPA were not detected in plasma NEFA. Plasma TAG-LA (control 2.6-fold, LPD 3·2-fold), AA (control 2.2-fold, LPD 1.6-fold) and DHA (control 2-3-fold, LPD 3·3-fold) concentrations were significantly greater in pregnant animals compared with non-pregnant rats (Table 5). There were no significant effects of dietary protein intake on plasma TAG-LA or -AA levels. However, plasma TAG-DHA concentration in pregnancy was significantly lower $(28.6 \%)$ in the mothers fed the LPD compared with controls (Table 5).

\section{Effect of reduced maternal protein intake in pregnancy on fetal liver and brain lipid compositions}

Fetal liver and brain total lipid concentrations are summarised in Table 6. There was no effect of maternal dietary protein intake on fetal liver PC, PE or TAG concentration. There was also no significant difference in the LCPUFA content of liver PC or PE between fetuses of mothers fed control or LPD diets. However, LA concentration was greater $(2 \cdot 0$-fold) in liver TAG of fetuses from mothers fed the LPD compared with controls. Brain PE concentration was significantly $(P<0 \cdot 01)$ less $(17.5 \%)$ in fetuses from mothers fed the LPD compared with controls, although there was no difference in brain PC concentration between dietary groups (Table 7). Analysis of the LCPUFA 
Table 4. Adult liver phospholipid and triacylglycerol (TAG) long-chain polyunsaturated fatty acid (LCPUFA) compositionsł

(Mean values and standard deviations for five rats per group)

\begin{tabular}{|c|c|c|c|c|c|c|c|c|}
\hline & \multicolumn{8}{|c|}{ Dietary group } \\
\hline & \multicolumn{4}{|c|}{ Control } & \multicolumn{4}{|c|}{ LPD } \\
\hline & \multicolumn{2}{|c|}{ Non-pregnant } & \multicolumn{2}{|c|}{ Pregnant } & \multicolumn{2}{|c|}{ Non-pregnant } & \multicolumn{2}{|c|}{ Pregnant } \\
\hline & Mean & SD & Mean & SD & Mean & SD & Mean & SD \\
\hline \multicolumn{9}{|c|}{$\mathrm{PC}(\mathrm{nmol} / \mathrm{g})$} \\
\hline LA & 1759 & 438 & 1822 & 157 & 1508 & 93 & 1494 & 140 \\
\hline DGLA & 94 & 20 & $55^{\star \star}$ & 8 & 88 & 22 & $57^{\star \star \star}$ & 4 \\
\hline AA & 4908 & 109 & $3288^{\star \star *}$ & 292 & 4278 & 298 & $2850^{\star *}$ & 283 \\
\hline DPA & 66 & 16 & $33^{\star \star \star}$ & 10 & 66 & 11 & $34^{\star \star *}$ & 8 \\
\hline DHA & 1241 & 236 & $1727^{\star \star \star}$ & 180 & 1058 & 149 & 991 & 195 \\
\hline \multicolumn{9}{|c|}{$\mathrm{PE}(\mathrm{nmol} / \mathrm{g})$} \\
\hline LA & 335 & 111 & $223^{\star \star}$ & 63 & 270 & 105 & 170 & 32 \\
\hline DGLA & 20 & 3 & $11^{* *}$ & 2 & 23 & 3 & $11^{\star *}$ & 1 \\
\hline AA & 1471 & 438 & $817^{\star \star *}$ & 34 & 1214 & 426 & $721^{\star \star \star}$ & 73 \\
\hline DPA & 50 & 16 & $25^{\star \star \star}$ & 5 & 51 & 8 & $20^{\star \star \star}$ & 6 \\
\hline DHA & 703 & 187 & $410^{* \star *}$ & 306 & 542 & 187 & $306^{\star \star \star}$ & 86 \\
\hline \multicolumn{9}{|c|}{ TAG $(\mathrm{nmol} / \mathrm{g})$} \\
\hline LA & 583 & 132 & 761 & 99 & 601 & 167 & 868 & 102 \\
\hline DGLA & 12 & 7 & 10 & 3 & $6^{\star \star \star \star}$ & 2 & 15 & 5 \\
\hline$A A$ & 57 & 14 & 39 & 14 & 41 & 11 & 27 & 16 \\
\hline DHA & 14 & 3 & 14 & 6 & 15 & 2 & 16 & 6 \\
\hline
\end{tabular}

LPD, low-protein diet; PC, phosphatidylcholine; LA, linoleic acid; DGLA, dihomo- $\gamma$-linolenic acid; AA, arachidonic acid; DPA, docosapentaenoic acid; DHA, docosahexaenoic acid; TAG, triacylglycerol.

Mean values were significantly different from those of non-pregnant animals within the same dietary group: ${ }^{* *} P<0.01,{ }^{* * *} P<0.005$.

Mean value was significantly different from that of the control-diet group for either non-pregnant or pregnant animals: ${ }^{* * * *} P<0.0001$.

‡For details of diets and procedures, see Table 1 and pp. 380-381.

Table 5. Adult plasma phosphatidylcholine (PC), non-esterified fatty acids (NEFA) and triacylglycerol (TAG) long-chain polyunsaturated fatty acid (LCPUFA) compositionsł

(Mean values and standard deviations for five rats per group)

\begin{tabular}{|c|c|c|c|c|c|c|c|c|}
\hline & \multicolumn{8}{|c|}{ Dietary group } \\
\hline & \multicolumn{4}{|c|}{ Control } & \multicolumn{4}{|c|}{ LPD } \\
\hline & \multicolumn{2}{|c|}{ Non-pregnant } & \multicolumn{2}{|c|}{ Pregnant } & \multicolumn{2}{|c|}{ Non-pregnant } & \multicolumn{2}{|c|}{ Pregnant } \\
\hline & Mean & SD & Mean & SD & Mean & SD & Mean & SD \\
\hline \multicolumn{9}{|c|}{$\mathrm{PC}(\mu \mathrm{mol} / \mathrm{l})$} \\
\hline LA & 166 & 39 & 181 & 36 & 184 & 35 & 246 & 38 \\
\hline DGLA & 5 & 1 & 3 & 1 & 6 & 2 & 5 & \\
\hline AA & 211 & 23 & 149 & 40 & 214 & 31 & 197 & 38 \\
\hline DPA & 3 & 1 & 2 & 1 & 3 & 1 & 2 & \\
\hline DHA & 40 & 5 & $72^{\star \star \star}$ & 7 & 39 & 5 & $58^{* \star} \dagger$ & \\
\hline \multicolumn{9}{|c|}{ NEFA $(\mu \mathrm{mol} / \mathrm{l})$} \\
\hline LA & 27 & 8 & 39 & 3 & 34 & 1 & 41 & 8 \\
\hline AA & 6 & 1 & 6 & 2 & 6 & 1 & 11 & \\
\hline DHA & 1 & 0 & 2 & 1 & 1 & 1 & 2 & \\
\hline \multicolumn{9}{|c|}{ TAG $(\mu \mathrm{mol} / \mathrm{l})$} \\
\hline LA & 463 & 186 & $1218^{\star \star \star}$ & 192 & 365 & 117 & $1162^{\star \star \star}$ & 315 \\
\hline DGLA & 5 & 3 & 7 & 2 & 3 & 1 & 8 & \\
\hline AA & 31 & 8 & $67^{\star * \star}$ & 15 & 34 & 6 & $56^{\star \star}$ & 9 \\
\hline DPA & 2 & 1 & 2 & 2 & 1 & 1 & 2 & 2 \\
\hline $\mathrm{DHA}$ & 6 & 2 & $14^{* * *}$ & 3 & 3 & 2 & $10^{* * *} \dagger †$ & 1 \\
\hline
\end{tabular}

LPD, low-protein diet; LA, linoleic aicd; DGLA, dihomo- $\gamma$-linolenic acid; AA, arachidonic acid; DPA, docosapentaenoic acid; DHA, docosahexaenoic acid; NEFA, non-esterified fatty acid; TAG, triacylglycerol; PC, phosphatidylcholine.

Mean values were significantly different from those of non-pregnant animals within the same dietary group: ${ }^{\star \star} P<0.01,{ }^{* \star \star} P<0.0001$.

Mean values were significantly different from those of the control-diet group for either non-pregnant or pregnant animals: $\dagger P<0.05, \dagger \dagger P<0.01$.

† For details of diets and procedures, see Table 1 and pp. 380-381. 
Table 6. Fetal liver phosphatidylcholine (PC), phosphatidylethanolamine (PE) and triacylglycerol (TAG) long-chain polyunsaturated fatty acid (LCPUFA) compositions $†$

(Mean values and standard deviations for five rats per group)

\begin{tabular}{lrrrr}
\hline & \multicolumn{4}{c}{ Dietary group } \\
\cline { 2 - 3 } & \multicolumn{2}{c}{ Control } & & LPD \\
\cline { 2 - 3 } \cline { 5 - 6 } & Mean & SD & & Mean \\
\hline PC (nmol/g) & & & & SD \\
LA & 645 & 148 & 642 & 107 \\
DGLA & 72 & 12 & 67 & 13 \\
AA & 720 & 120 & 642 & 107 \\
DPA & 17 & 6 & 18 & 5 \\
DHA & 243 & 62 & 241 & 97 \\
Total FA & 5900 & 1800 & 5600 & 1300 \\
PE (nmol/g) & & & & \\
LA & 141 & 30 & 145 & 23 \\
DGLA & 20 & 3 & 20 & 3 \\
AA & 545 & 87 & 581 & 74 \\
DPA & 14 & 3 & 18 & 5 \\
DHA & 219 & 46 & 248 & 48 \\
Total FA & 2200 & 300 & 2300 & 300 \\
TAG (nmol/g) & & & & \\
LA & 57 & 27 & $115^{\star *}$ & 40 \\
AA & 17 & 6 & 17 & 7 \\
DHA & 15 & 5 & 12 & 5 \\
Total FA $\ddagger$ & 700 & 300 & 800 & 300 \\
\hline
\end{tabular}

LPD, low-protein diet; PC, phosphatidylcholine; LA, linoleic aicd; DGLA, dihomo- $\gamma$-linolenic acid; AA, arachidonic acid; DPA, docosapentaenoic acid; DHA, docosahexaenoic acid; TAG, triacylglycerol.

Mean value was significantly different from that of the control-diet group: ${ }^{* *} P<0.01$

†For details of diets and procedures, see Table 1 and pp. 380-381.

$¥$ Total FA represents the sum of all FA within the lipid fraction, including saturated and monounsaturated species.

Table 7. Fetal brain phosphatidylcholine (PC), and phosphatidylethanolamine (PE), long-chain polyunsaturated fatty acid (LCPUFA) compositions†

(Mean values and standard deviations for five rats per group)

\begin{tabular}{lrrrr}
\hline & \multicolumn{4}{c}{ Dietary group } \\
\cline { 2 - 3 } & \multicolumn{2}{c}{ Control } & & \multicolumn{2}{c}{ LPD } \\
\cline { 2 - 3 } \cline { 5 - 6 } & Mean & SD & & Mean \\
\hline PC (nmol/g) & & & & SD \\
LA & 69 & 12 & 64 & 15 \\
DGLA & 22 & 6 & 19 & 5 \\
AA & 633 & 97 & 613 & 111 \\
DHA & 314 & 61 & $232^{\star *}$ & 46 \\
Total FA & 7500 & 600 & 7400 & 700 \\
PE (nmol/g) & & & & \\
LA & 49 & 28 & 59 & 24 \\
AA & 704 & 83 & 730 & 68 \\
DHA & 558 & 87 & $415^{\star *}$ & 69 \\
Total FA & 4000 & 900 & $3300^{\star *}$ & 300 \\
\hline
\end{tabular}

LPD, low-protein diet; PC, phosphatidylcholine; LA, linoleic aicd; DGLA, dihomo- $\gamma$-linolenic acid; AA, arachidonic acid; DHA, docosahexaenoic acid; FA, fatty acid; PE, phosphatidylethanolamine.

Mean values were significantly different from those of the control-diet group: ${ }^{\star \star} P<0.01$.

†For details of diets and procedures, see Table 1 and pp. 380-381.

$\ddagger$ Total FA represents the sum of all fatty acids within the lipid fraction, including saturated and monounsaturated species. composition of fetal brain $\mathrm{PC}$ and $\mathrm{PE}$ showed that there was no significant difference in the concentrations of $n-6$ fatty acids between dietary groups (Table 7). In contrast, DHA concentration was significantly $(P<0.01)$ lower in both brain PC $(26.1 \%)$ and PE $(25.6 \%)$ in fetuses from mother fed the LPD. Only $17.5 \%$ of the reduction in brain PE-DHA could be accounted for by the decrease in brain total $\mathrm{PE}$, indicating that there was a specific effect of LPD on DHA levels independent of total PE concentration.

\section{Discussion}

The results of the present study demonstrate that following the consumption of a diet which provided $90 \mathrm{~g}$ protein $/ \mathrm{kg}$ for $20 \mathrm{~d}$, there were no gross differences in the non-pregnant or pregnant animals, compared with the diet providing $180 \mathrm{~g}$ protein $/ \mathrm{kg}$. Nevertheless, our present results show that reducing maternal dietary protein intake in pregnancy resulted in a lower concentration of DHA in maternal liver and plasma and impaired accumulation of DHA into fetal brain phospholipids. ALNA was the sole source of $n-3$ fatty acids in the diet of these rats and therefore the results provide clear evidence that feeding the LPD compromised one or more of the metabolic-physiological steps involved in the formation and/or supply of DHA from mother to fetus. This is a novel observation, and since accumulation of DHA into the developing central nervous system results in long-term impairment of neurological function (Connor et al. 1990; Riesbick et al. 1990, 1994; Innis, 1991), it raises the possibility that such deficits represent an insult to the development and subsequent function of fetal brain.

Feeding the LPD did not alter significantly the weight of the non-pregnant animals or the weight gain of the pregnant rats. Neither was there a significant difference in liver weight between dietary groups in either the non-pregnant or pregnant rats. Thus a $50 \%$ reduction in protein intake did not restrict the growth of the adult animals. Furthermore, there were no significant effects of the LPD on liver or plasma total lipid concentrations This is in contrast to previous studies where a more severe protein restriction $(80 \%)$ resulted in accumulation of TAG and lower PC levels in liver tissue accompanied by decreased plasma TAG concentration in non-pregnant rats (Ristic et al. 1985), presumably due to impaired mobilisation of TAG by VLDL. Together, these results indicate that feeding a diet with a moderately reduced protein content did not produce marked changes in lipid handling in the adult rat. In particular, there was no apparent impairment of the capacity of the liver to maintain membranes, to export lipoproteins and to sustain the increased plasma TAG concentration associated with late gestation.

There was no effect of the LPD in non-pregnant rats on the LCPUFA composition of liver PC, PE or TAG or plasma PC, TAG and NEFA. Since the fat source in both control and LPD diets did not contain AA or DHA, tissue levels of these fatty acids reflect metabolic capacity for their synthesis from LA and ALNA respectively. These results indicate that in non-pregnant females the activities of the desaturation-elongation pathways responsible for 
LA and ALNA inter-conversion were adequate to meet the demand on the reduced-protein intake. From the present results, it is not possible to say whether there was any effect at all of the LPD, as the demands for AA and DHA may be relatively low in non-pregnant adults, such that any changes in capacity for LA and ALNA inter-conversion were insufficient to limit adequate availability of LCPUFA for membrane synthesis.

During pregnancy, the demands for LCPUFA are increased above those of the non-pregnant adult female, to support the development of the fetus and placenta. The rats consumed a diet lacking AA and DHA and therefore any increased demands for these fatty acids by fetal tissues would have to have been met by adaptations to maternal lipid metabolism. Pregnancy was associated with selective changes in the LCPUFA concentrations in maternal liver and plasma. In particular, liver PC from pregnant animals fed the control diet contained less DGLA, AA and DPA than non-pregnant animals. Maternal liver PE- $n-6$ and $-n-3$ LCPUFA concentrations were also lower in pregnant animals, while there was no effect of pregnancy on liver TAG-LCPUFA composition. In contrast, plasma PC, DGLA, AA and DPA levels were not significantly different at term compared with non-pregnant rats. Plasma TAG-LA, -AA and-DHA concentrations were increased in pregnancy. One possible explanation for the different patterns of pregnancy-associated changes in lipid composition is selective incorporation of individual LCPUFA species into different hepatic lipid pools destined either for incorporation into tissue or mobilisation from the liver.

DHA concentration was significantly greater in both hepatic and plasma PC, and in plasma TAG in pregnant animals fed the control diet compared with non-pregnant rats. Increased plasma PC-DHA concentration is, in part, the result of selective adaptation to maternal hepatic PC synthesis (Burdge et al. 1994), which may increase the availability of DHA to the placenta and/or mammary gland. In the absence of an increased dietary intake, increased availability of DHA would be achieved by mobilisation of DHA from adipose tissue, and/or up-regulation of ALNA inter-conversion, either of which would require increased activity of enzymes and transport proteins involved in these pathways. In contrast, in the pregnant rats fed the LPD there was no increase in the DHA content of hepatic PC above those found in non-pregnant animals, and there was a lower increment in both plasma PC- and TAG-DHA. This finding is consistent with the suggestion that feeding the LPD had an adverse effect and was a limitation in the mechanisms responsible for modulating the tissue and plasma levels of DHA that only became manifest when the biochemical-physiological processes were stressed by increased demands for DHA associated with pregnancy. Feeding pregnant rats a diet containing $50 \mathrm{~g}$ protein $/ \mathrm{kg}$ has been shown to decrease the activity of the rate-limiting hepatic enzyme $\Delta 6$-desaturase in late gestation and during lactation (De Thomas et al. 1983), which may explain the reduced DHA levels in liver phospholipid in the pups at weaning in the pups (De Thomas et al. 1983). Both DHA and AA are products of the same pathway (Sprecher et al. 1999) and if, therefore, a reduction in $\Delta 6$-desaturase activity was the primary mechanism for reduced DHA status in pregnant rats, then it would be expected that hepatic and plasma AA levels would also be lower in the LPD group. Alternatively, a specific effect on DHA, which was not seen for AA, could be explained by selective down-regulation of the $\Delta 6$-desaturase responsible for conversion of $24: 5 n-3$ to $24: 6 n-3$ and/or the peroxisomal $\beta$-oxidation step which is required for DHA, but not AA, synthesis.

There were no effects of the LPD during pregnancy on placental or fetal carcass weight, fetal liver weight, total phospholipid and TAG, nor LCPUFA concentrations. These results differ from those found in other studies that showed decreased levels of DHA and/or AA in rat liver phospholipids, measured at weaning or 3 months of age (De Thomas et al. 1983; Ozanne et al. 1998). These differences may be explained by the different ages at which the studies were carried out, or may be related to a more severe reduction in protein intake (De Thomas et al. 1983), producing more severe effects on lipid metabolism (Marin et al. 1995).

There was no significant effect of reduced maternal protein intake on fetal brain growth. In contrast, fetuses from mothers fed the LPD showed decreased brain PE concentration and a specific reduction in PC- and PE-DHA contents compared with controls. Marin et al. (1995) showed that brain weight at weaning was reduced in pups from mothers fed a LPD compared with controls. Since brain growth in the rat occurs principally during the period between birth and weaning (Dobbing \& Sands, 1979), the absence of any such effect on growth in the current study may reflect the age at which the animals were studied. The selective reduction in brain total PE concentration is consistent with the lower total lipid-P reported previously (Marin et al. 1995). The significance of a proportional increase in brain PC: PE in may be indicative of altered brain structure and function, and this will need to be investigated further. In guinea-pigs ingesting ethanol during pregnancy, the PC: PE value in fetal brain at term was increased and was associated with altered motor function (Burdge \& Postle, 1995b).

The substantial accumulation of DHA into the phospholipids in the developing fetal and neonatal brain and retina is an aspect of functional maturation. Deficits in brain and retinal DHA assimilation are associated with impaired neurological function (Neuringer et al. 1984; Neuringer et al. 1988; Connor et al. 1990; Innis, 1991). Fetuses of mothers fed the LPD had significantly $(P<0.01)$ lower brain PC- and PE-DHA concentrations, which raises the real possibility that this intervention might have been associated with impaired maturation or neurological dysfunction. The magnitude of the difference between dietary groups in fetal brain PE-DHA concentration (about 25\%) was greater than reported for rat pups at weaning from mothers fed an ALNA- and DHA-deficient diet during pregnancy (14\%; Leat et al. 1986). One possible explanation is that the pregnant rat fed an $n-3$ fatty acid-deficient diet is able to meet the demands of the fetus for DHA in part by mobilisation of fatty acid stores. In contrast, the apparent constraints on $n-3$ fatty acid handling in pregnancy associated with the LPD suggest that the ability of 
the mother to adapt her essential fatty acid metabolism during gestation may be a greater determinant of DHA accretion in fetal brain than dietary $n$-3 LCPUFA intake. However, as the majority (93\%) of DHA accumulation and neuritogenesis in rat brain occurs during the sucking period (Kishimoto et al. 1965; Sinclair \& Crawford, 1972), any limitation in DHA assimilation during late fetal life may be offset in part by DHA provision during lactation. While fetal brain-phospholipid composition and DHA content were altered significantly by feeding the mother the LPD, there was no effect on fetal liver-lipid composition. This suggests that the developing fetal brain is more sensitive than liver to impaired maternal DHA. Langley-Evans et al. (1996) showed that the effect of altered maternal protein intake on the programming of blood pressure in the rat could be modified by the type of oil used in the feed. Whether the adverse impact of the LPD diet on maternal and fetal DHA status can be modified in a similar manner remains to be determined.

The results of the present study show that in rats fed a diet lacking DHA, reducing protein intake in pregnancy decreased both maternal DHA status and accumulation of DHA into fetal brain. Whether variation in maternal protein intake is an important determinant of DHA supply from mother to fetus in pregnant women consuming both ALNA and DHA remains to be determined. The pregnancy-associated increase in plasma phospholipids-DHA concentration (Postle et al. 1995; Otto et al. 1997) suggests that the capacity to up-regulate LCPUFA synthesis and mobilisation may be a primary factor in determining DHA supply to the fetus and neonate. If so, it will be important to identify the extent to which the observed variation between women in the increment of plasma phospholipid DHA during pregnancy (about 25\%) (Postle et al. 1995; Otto et al. 1997) can be accounted for by differences in dietary protein intake. It remains to be established whether such variations in maternal DHA status are associated with differences in neurological function in the offspring.

\section{Acknowledgement}

The authors wish to acknowledge the assistance of $\mathrm{Mr}$ $\mathrm{P}$. Wright in preparation of specimens for GC analysis.

\section{References}

Burdge GC, Hunt AN \& Postle AD (1994) Mechanisms of hepatic phosphatidylcholine synthesis in adult rat: effects of pregnancy. Biochemical Journal 303, 941-947.

Burdge GC \& Postle AD (1994) Hepatic phospholipid molecular species in the guinea pig. Adaptations to pregnancy. Lipids 29, 259-264.

Burdge GC \& Postle AD (1995a) Phospholipid molecular species composition of developing fetal guinea pig brain. Lipids 30, $719-724$.

Burdge GC \& Postle AD (1995b) Effect of maternal ethanol consumption during pregnancy on the phospholipid molecular species composition of fetal guinea-pig brain, liver and plasma. Biochimica et Biophysica Acta 1256, 346-352.

Burdge GC, Wright P, Jones AE \& Wootton SA (2000) A method for separation of phosphatidylcholine, triacylglycerol, nonesterified fatty acids and cholesterol esters from plasma by solid-phase extraction. British Journal of Nutrition 84, $781-787$.

Carnielli VP, Wattimena DJL, Luijendijk IHT, Boerlage HJ \& Sauer PJJ (1996) The very low birth weight premature infant is capable of synthesizing arachidonic and docosahexaenoic acid from linoleic and linolenic acid. Pediatric Research 40, 169-174.

Chambaz J, Ravel D, Manier MC, Pepin D, Mulliez N \& Bereziat G (1985) Essential fatty acid interconversion in the human liver. Biology of the Neonate 47, 136-140.

Chen Z-Y, Yang J \& Cunnane SC (1992) Gestational hyperlipidaemia in the rat is characterised by accumulation of $n-6$ and $n-3$ fatty acids, especially docosahexaenoic acid. Biochimica et Biophysical Acta 1127, 263-269.

Clandinin MT, Chapell JE, Leong S, Heim T, Swyer PR \& Chance GW (1980a) Intrauterine fatty acid accretion rates in human brain: implications for fatty acid requirements. Early Human Development 4, 121-129.

Clandinin MT, Chapell JE, Leong S, Heim T, Swyer PR \& Chance GW (1980) Extrauterine fatty acid accretion in infant brain: implications for fatty acid requirements. Early Human Development 4, 131-138.

Connor WE, Neuringer M \& Lin DS (1990) Dietary effects on brain fatty acid composition: the reversibility of $n-3$ deficiency and turnover of docosahexaenoic acid in the brain, erythrocytes and plasma of rhesus monkeys. Journal of Lipid Research 31, 237-247.

Crawford MA, Hassam AG, Hall BM \& Williams G (1976) Essential fatty acids and fetal brain growth. Lancet 1, 452-453.

De Thomas ME, Mercuri O \& Serres C (1983) Effect of crossfostering rats at birth on the normal supply of essential fatty acids during protein deficiency. Journal of Nutrition 113, 314-319.

Demmelmair H, v. Schenck U, Behrendt E, Sauerwald T \& Koletzko B (1995) Estimation of arachidonic acid synthesis in full term neonates using natural variation of $13 \mathrm{C}$ content. Journal of Pediatric Gastroenterology and Nutrition 21, $31-36$.

Dobbing J \& Sands J (1979) Comparative aspects of the brain growth spurt. Early Human Development 3, 79-83.

Folch J, Lees M \& Sloane-Stanley GH (1957) A simple method for the isolation and purification of total lipides from animal tissues. Journal of Biological Chemistry 226, 497-509.

Innis SM (1991) Essential fatty acids in growth and development. Progress in Lipid Research 30, 39-103.

Jackson AA, Philips G, McClelland I \& Jahoor F (2001) Synthesis of hepatic secretary proteins in normal adults consuming a diet marginally adequate in protein. American Journal of Physiology 281, G1179-G1187.

Kishimoto Y, Davies WE \& Radin NS (1965) Developing rat brain: changes in cholesterol, galactolipids, and the individual fatty acids of gangliosides and glycerophosphotidates. Journal of Lipid Research 6, 532-536.

Koletzko B \& Braun M (1991) Arachidonic acid and early human growth: Is there a relation. Annals of Nutrition and Metabolism 35, $128-131$.

Langley SC \& Jackson AA (1994) Increased systolic blood pressure in adult rats induced by foetal exposure to maternal low protein diet. Clinical Science 86, 217-222.

Langley-Evans SC, Clamp AG, Grimble RF \& Jackson AA (1996) Influence of dietary fats upon systolic blood pressure in the rat. International Journal of Food Sciences and Nutrition 47, 417-425.

Langley-Evans SC, Sherman RL, Welham SJM, Nwagwu MO, Gardiner DS \& Jackson AA (1999) Intrauterine programming 
of hypertension: the role of the renin-angiotensin system. Biochemical Society Transactions 27, 88-93.

Leaf AA, Leighfield MJ, Costeloe KL \& Crawford MA (1992) Long chain polyunsaturated fatty acids and fetal growth. Early Human Development 30, 183-191.

Leat WMF, Curtis R, Millicham NJ \& Cox RW (1986) Retinal function in rats and guinea-pigs reared on diets low in essential fatty acids and supplemented with linoleic or linolenic acids. Annals of Nutrition and Metabolism 30, 166-174.

Li Z, Kaplan ML \& Hatchey DL (2000) Hepatic microsomal and peroxisomal docosahexaenoate biosynthesis during piglet development. Lipids 35, 1325-1333.

Marin MC, De Thomas ME, Serres C \& Mercuri O (1995) Protein-energy malnutrition during gestation and lactation in rats affects growth rate, brain development and essential fatty acid metabolism. Journal of Nutrition 125, 1017-1024.

Neuringer M, Anderson GJ \& Connor WE (1988) The essentiality of $n-3$ fatty acids for the development and function of the retina and brain. Annual Review of Nutrition 8, 517-541.

Neuringer M, Connor WE, Van Petten C \& Barstrad L (1984) Dietary omega-3 fatty acid deficiency and visual loss in infant rhesus monkeys. Journal of Clinical Investigation 73, 272-276.

Otto SJ, van Houwelingen AC, Manninen A, Godfrey K, LopezJaramillo P \& Hornstra G (1997) Maternal and neonatal essential fatty acid status in phospholipids: an international comparative study. European Journal of Clinical Nutrition 51, 232-242.

Ozanne SE, Martinsz ND, Petry CJ, Loizou CL \& Hales CN (1998) Maternal low protein diet in rats programmes fatty acids desaturase activities in the offspring. Diabetologica 41, $1337-1342$

Peluffo RO \& Brenner RR (1974) Influence of dietary protein on 6- and 9-desaturation of fatty acids in rats of different ages and in different seasons. Journal of Nutrition 104, 894-900.

Postle AD, Al MDM, Burdge GC \& Hornstra G (1995) The composition of individual molecular species of plasma phosphatidylcholine in human pregnancy. Early Human Development 43, 47-58.

Reisbick S, Neuringer M, Hasnain R \& Connor WE (1990) Polydipsia in rhesus monkeys deficient in omega-3 fatty acids. Physiology of Behaviour 47, 315-323.
Reisbick S, Neuringer M, Hasnain R \& Connor WE (1994) Home cage behaviour of rhesus monkeys with long-term deficieny of omega-3 fatty acids. Physiology of Behaviour 55, $231-239$.

Ristic V, Petrovic G \& Ristic M (1985) Effect of a low protein diet on the serum and liver lipid content of rats. Acta Medica Iugoslavica 39, 117-123.

Salem N \& Niebylski CD (1995) The nervous system has an absolute molecular species requirement for proper function. Molecular Membrane Biology 12, 131-134.

Salem N, Wegher B, Mena P \& Uauy R (1996) Arachidonic and docosahexaenoic acids are biosynthesised from their 18-carbon precursors in human infants. Proceedings of the National Academy of Sciences USA 93, 49-54.

Sanders TAB \& Rana SK (1987) Comparison of the metabolism of linoleic and linolenic acids in the fetal rat. Annals of Nutrition and Metabolism 31, 349-353.

Sauerwald TU, Hachey DL, Jensen CL, Chen H, Anderson RE \& Heird WC (1997) Intermediates in endogenous synthesis of $\mathrm{C} 22: 6 \omega 3$ and $\mathrm{C} 20: 4 \omega 6$ by term and preterm infants. Pediatric Research 41, 183-187.

Sinclair AJ \& Crawford MA (1972) The accumulation of arachidonate and docosahexaenoate in the developing rat brain. Journal of Neurochemistry 19, 1753-1758.

Sprecher H, Chen Q \& Yin FQ (1999) Regulation of the biosynthesis of $22: 5 n-6$ and $22: 6 n-3-$ a complex intracellular process. Lipids 34, 153-156.

Su HM, Bernardo L, Mirmiran M, Ma XH, Corso TN, Nathanielsz PW \& Brenna JT (1999) Bioequivalence of dietary alpha-linolenic and docosahexaenoic acids as sources of docosahexaenoate accretion in brain and associated organs of neonatal baboons. Pediatric Research 45, 87-93.

Su HM, Bernardo L, Mirmiran M, Ma XH, Nathanielsz PW \& Brenna JT (1999) Dietary 18:3n-3 and 22:6n-3 as sources of 22: $6 n-3$ accretion in neonatal baboon brain and associated organs. Lipids 34, Suppl., S347-S350.

Uauy RD, Birch DG, Birch EE, Tyson JE \& Hoffman DR (1990) Effect of dietary omega-3 fatty acids on retinal function of very-low-birth-weight neonates. Pediatric Research 28, 485-492. 